\title{
THE CARE OF THE DYING*
}

\author{
By CLIFFORD HOYLE, M.D., F.R.C.P. \\ (Asst. Phys. King's College Hospital and Brompton Hospital.)
}

The Care of the Dying is a suitable subject for a lecture because of its importance, and also as it receives so little notice in our professional training and in the literature. Clinical practice, of whatever kind, brings to all of us responsibility for the dying; and not a little of the doctor's art can be shown by the resource displayed in their care. When Swinburne wrote that "Peace, rest and sleep are all we know of death" he defined also the needs of the dying; and the measure of our success in caring for them is the continuity with which those needs are fulfilled.

Although some patients become aware of the imminence of death, to a majority it seems to be denied, a piece of fortune epitomised in Palmerston's famous remark on his death bed, "Die, my dear doctor, That's the last thing I shall do!" There are many reasons why this should be: an important one is lack of knowledge about the state of affairs, and this supplies a special motive for not disclosing more than is good for the patient. Then the will to live, the human capacity for optimism, and the deceptions practised upon mentality by illness itself help to mask truth; and if they are not always entirely successful it is, at any rate, a striking thing how rarely the dying appear to grasp their situation. They are occupied with symptoms rather than portents.

But it is a duty in prognosis not only to calculate the chances of a fatality in serious illness, but also to recognise the signs of approaching death. They are easily overlooked. Even death itself may remain unsuspected at an examination unless the possibility is in mind. Just as it shows by cessation of breathing and of heart sounds, so the approach is gauged from the behaviour of respiration, pulse and blood pressure, the colour, coldness and opacity of the skin and the state of consciousness. Subsúltus and a wandering delirium may give earlier warning, or a subnormal or mounting temperature, a clammy sweat and loss of sphincter control. Now and then, as in the influenzal pneumonias, a "death rattle" from tracheal secretions is the ominous sign; or in shock the placid state of a patient gravely ill.

But whatever your impression of the nearness of death guard against restricted forecasts, for they will be wrong. Sometimes it is difficult to avoid prediction, but we are entitled not to set bounds to a matter fraught with uncertainty. Night rather than day, the small hours of the morning most often so it is said, and as a rule a quiet end, pictured in the lines,

"Her suffering ended with the day;
Yet lived she at its close,
And breathed the long long night away
In statue-like repose."

Special warning applies to those with mental derangement, for they can survive expectedly fatal illness in the most astonishing way, perhaps because they often miss the suffering which adds so much to the changes wrought by physical disease. The will to live plays a vital part in serious illness; quite commonly patients last for days, or even weeks, beyond reasonable expectation of life, and occasionally recover from a position apparently hopeless. said:

But it is not the time so much as the manner of death which matters. As Edmund Cooke

\footnotetext{
"Death comes with a crawl, or comes with a pounce,

But whether he's slow or spry,

It isn't the fact that you're dead that counts,

But only, how did you die?"
}

Doctors and clergymen die badly, publicans well. The easy deaths are those where consciousness goes early, the sudden death or the comatose death: next to these the quiet deaths, so common among the elderly and the insane, who fade away into the grave literally. Toxic deaths are characteristic, with great wasting and muscular hypotonus, dim sunken, half-closed eyes, pinched nose, dropped jaw, arid mouth with blackened sordes over the lips and tongue, an ashen cold clammy skin, and high fever subsiding when a racing pulse and mental hebetude

* Based upon a lecture given at Horton Hospital, November I94I. 
herald the close. Almost always these patients have suffered their worst some time before the end, and not often do they call for much relief in the last stages. The dying patients who tax our skill are those with surviving consciousness who are struggling with asphyxia or with pain. Even so there is evidence of considerable dimming of consciousness at the time of real or apparent suffering, a point made again recently by Ryle (I940).

Turning now to the actual care of the dying, many of their needs are common to all sick and bed-ridden patients. But, as our aim should be to make dying as easy as possible, assuaging symptoms and securing comfort have to take the foremost place. This often requires decisions that would be unjustified with a prospect of survival, for the relief of symptoms can demand treatment that may shorten life. But to make such decisions, to adhere to them, and sometimes to persuade others of their wisdom is an obligation to these patients. First, as a matter of policy, we must avoid doing harm. Doing harm is a wide term; it includes belated attempts at remedial treatment and measures likely to increase discomfort, such as useless moves or recourse to dangerous or toxic drugs when their time has clearly passed. It includes also the subjection of dying folk to dramatic but indulgent surgery, or to investigations of no practical value. Try to avoid vigorous fiddling; not only is it often ill judged, but it may invite criticism. Many of the cynical remarks about doctors caricature this point. "Young doctors kill their patients, old doctors allow them to die." Joseph Zabara, author of The Book of Delights, written in the thirteenth century, added a sting in his saying "A doctor and the Angel of Death both kill, but the former charges a fee." Another quip recorded by Parkes Weber (I9I8), is in the story that when Napoleon, during a fit of despondency, remarked that he would forsake war and turn physician, the sarcastic Tallyrand whispered to the bystanders, "Toujours, assassin."

Next to an avoidance of harm in the care of the dying by far the most important matter is the relief of distress, usually pain or suffocation. The dying man ought to reach unconsciousness as leniently, and if necessary as quickly as possible. Occasionally there is a place, as an emergency measure, for an intravenous or volatile anaesthetic, in strychnine poisoning or tetanus for instance. Sometimes special measures avoid particular symptoms, as the tapping of recurring pleural effusions or a gastrostomy for oesophageal growth. But in general the best relief comes from the group of drugs which depress cortical activity-opiates, hypnotics, alcohol, and hyoscine.

Opium, with its derivatives, still stands out head and shoulders as in the days of Sydenham's dictum that few would have the temerity to practise physic without its aid. It owes this unique value to a highly selective action upon the sensory receptors of the brain. Morphine, in ordinary full doses, $\frac{1}{4}$ gr. to $\frac{1}{3}$ gr. selectively relieves pain, especially constant pain, for it lessens the power of attention without producing deep narcosis. Often morphine is not given adequately to the dying; a comfortable patient is the sole judge of the sufficiency of the dose, and of how often it should be repeated. At a time when morphine is the one means of giving relief, it is often withheld for fear of hastening death. But a therapeutic dose of morphine that proves fatal proves also by how fine a thread life remained suspended, and that death in any case was near at hand. In this connection we can remember the wise advice of Seneca, that death is sometimes a punishment, often a gift, but to many it is a favour. The occasions when morphine should be withheld do not concern the dying.

The manner of giving morphine is worth comment, for hypodermics are largely superfluous; a tablet dissolved under the tongue is equally effective, and almost as rapid. Now and then intravenous morphine is the only way. Opium, as powder, tincture, or nepenthe, has a longer action which is desirable. An old way of treating peritonitis mentioned by Burney Yeo (I908) was to give the equivalent of 2 gr. of opium followed by I gr. every hour until pain was relieved, a plan which can be copied with advantage for the use of opium in the dying. As tolerance comes the demands increase, but they should be satisfied, for habituation is irrelevant here. There is however this to be said about it, that until we have given opiates a few times on the scale needed by some of these patients it is a procedure apt to frighten the hardiest; for sometimes they eat the drug literally, and live on it-for the large quantities consumed certainly extend life at times.

None of the modern substitutes for opium and morphine, such as heroin, dilaudid, dicodid, and eukodal have any decided advantages in treating the dying. Heroin is of course strongly habit forming, but the other three have been advocated on the score that they do not produce this so rapidly. With drugs of this type habit is really an expression of euphoria and the less the tendency to habit the less euphoria found with therapeutic doses. Yet this is what we need so often in the dying, and its absence robs these substitutes of morphine of the same value. No 
analgesics of the coal tar series compare with morphine in effectiveness for relieving pain, though they play a useful part so long as pain is not an overwhelming symptom.

In a way morphine acts rather like alcohol so far as euphoria is concerned; but with alcohol euphoria is not paralleled by any such abolition of disagreeable sensory impressions as with morphine. Thus alcohol finds its chief use among the dying when physical discomfort is not great. It helps to take the edge off symptoms, to bolster up morale, however falsely, and to ease the mental depression which comes so often during a slow death. The choice of form should usually rest with the patient and his means; a double whisky or Holland's gin, rum in hot milk, port sweetened with sugar, a still wine, or favourite liqueur are worth suggesting. Champagne is an overrated drink, but it is most refreshing for a dirty mouth.

The use of hypnotics among the dying will soon accustom you to frequent failures. A common experience is to give these drugs in amounts thought to be ample, and yet find that sleep has been sought in vain. There are many reasons for failure: for instance, ordinary hypnotics almost have no effect in the presence of pain; another is that sometimes they are not absorbed, especially when the alimentary canal is disordered by serious illness. Then again tolerance has to be reckoned with. A dying patient already may be well habituated when pharmacopoeial doses have no standing. For these reasons we must be prepared to combine hypnotics with analgesics when there is pain, if necessary give them by injection, and adjust the dose to habituation. The choice is wide and gives scope for individual preference. Chloral hydrate is one of the best for it is remarkably potent, easily taken in dilution and almost free from tolerance. Sulphonal is uncertain because absorption is so variable and slow; but for some dying patients this ordinary disadvantage becomes a positive asset. All the barbitone group are easy to take, but individual members are more likely to fail within a short period of regular administration because tolerance is acquired so rapidly. But, as they are non-irritant and many are soluble, they can be given by injection; and if this is needed they are the hypnotics of choice, such as soluble phenobarbitone ( 2 gr.), sodium amytal (Io gr. or 0.6 gram in Io per cent solution given slowly intravenously), nembutal ( 3 to 5 gr. or 0.2 to 0.3 gram in ro mils intravenously), pernocton ( $x$ to 2 mils of a ro per cent solution intramuscularly), or somnifaine $e_{\circ}$ Paraldehyde can also be given intravenously on occasion, a drachm or two as a ro per cenf solution in physiological saline.

Hyoscine can be a helpful drug for the dying. Needing careful dosage-rarely more than $\frac{1}{10} \overline{0}$ gr. - with a reputation for uncertainty for it may lead to the delirium and restlessness of the belladonna allies, it still retains a significant place. Usually it creates a feeling of languor and drowsiness differing from that of ordinary hypnotics in not passing into deep sleep. Hyoscine has a selective effect upon memory. Patients under its influence cannot recall the names of common objects, for instance. Not only does it serve to ablate the recollection of an unnerving experience when used at the time, but also removes the consequences of such memory, dejection, or even despair. Thus hyoscine is worth using to minimise the remembrance of severe symptoms which are bound to recur, for example paroxysms of extreme pain or dyspnœa. Morphine with hyoscine is then the treatment of choice for attacks.

The value of depressant drugs is great, but after a while they sometimes seem to make a patient dying by inches utterly miserable. No one seeing much chronic illness can fail to have been impressed by this difficulty. These patients benefit from cocaine. Cocaine should never be given for its cerebral actions except to the dying, for habituation is pronounced; but judiciously used then it can be something of a sorcerer's philtre. Like morphine and hyoscine, it affects the cerebral cortex selectively, but chiefly as a stimulant to the lower levels of the sensorium concerned with emotional and physical sensation of a pleasurable kind. Patients under cocaine show exhilaration, even hilarity, and remain indifferent both to fatigue and discomfort short of actual pain. In the dying it does not relieve either pain or other distress, but it copes with the heritage of misery better than any other remedy. It can be given simply, or with morphine as a cocktail made with $\frac{1}{4}$ gr. of each alkaloid in a few drachms of gin flavoured with orange bitters, vermouth, or lime juice, or sweetened with honey or sugar. Special uses for cocaine, worth noting, depend upon its local anæsthetic action: the relief of pain from inoperable growths of the throat, oesophagus, or stomach, or from the laryngitis of advanced phthisis.

So far we have seen how much of the care of the dying turns upon abstaining from harm and allaying symptoms, and how much the latter is really a study in the therapeutics of a few drugs with a highly specialised action. Turning now to other matters not less important, first is the question of nursing. A good nurse is essential, for there are few patients who better test capa- 
bilities and temperament than one dying by inches. A decision as to whether a dying patient should be moved, either from or to his home, often centres upon the problem of nursing. Cost, home facilities, and the wishes of those concerned must decide. Private nursing is at least as expensive as a contributory ward at hospital, but cheaper than nursing home or private ward care. If expense is no consideration day and night nurses at home are often best for the last phase if proper facilities for their care, as well as the patient's, are available. For others illness can be managed with a district nurse fairly often when funds do not permit of more; if not, admission is needed to a local hospital or to one of the special homes for the dying. Discussion of nursing often turns 'upon how far relatives should take a hand. Apart from whether the person is properly trained, such a policy may be unwise; the work is heavy, the individual is rarely available as continuously as required, and the influence of a relative and her freedom of decision are rarely so complete as that of an independent person. Often too a burden of domestic as well as nursing cares falls upon the luckless volunteer, and for a close relative the experience of watching the dying continuously is a painful business. But there are the great advantages that the patient may prefer a relative, and that it gives that relative something useful to do.

A nurse's duties are manifold, including the care of the sick room with its ventilation and warmth, the toilet of the patient and his bed, adjustments of posture, attention to pressure points and the mouth, the selection and supervision of food, the securing of quiet, the handling of relatives and visitors, besides details of special treatment. Almost always the nurse's responsibility is greater than the doctor's at this stage, and an experienced nurse can safely take her choice with many actual details of treatment. She is constantly with the patient, and better tells the needs as they arise.

There are a few points with special interest, worth mention. In hospital the dying should be screened from other patients, or given a side room, more for the sake of their relatives and others than for themselves. There is no need to parade gloom before the end, so shaded lights and half drawn blinds are usually out of place. Whispered conversation in the hearing of the patient is never wise; for the dying hear when least expected, and a chance remark may do bitter harm. Before death is near at hand there is often no point on insistence upon rest in bed exclusively when patients desire otherwise; they can be carried to another room, or into a garden for a change of scene. However important a restriction of visitors may be during serious illness there is much less reason with the dying; and old friends should never be forbidden during these last days. Remember too that the doctor's own visits may have nothing to bring but hope and cheer; and although it is tempting to curtail their length and number it may be unkind to do so. "In the practice of our art it often matters little what medicine is given, but matters much that we give ourselves with pills," as Alfred Worcester remarks (I940).

A subservient insistence upon bed pans as a routine is out of place in the dying, though we should not let a patient suffer from impacted faeces any more than from an overdistended or dribbling bladder. For comfort and safety from bed sores, air rings and cushions or water beds are always needed, with support for the thighs by a donkey and for the heels by simple homemade rings of tow covered by wool and a bandage. Pillows should be properly adjusted as often as necessary to support the lumbar spine, and so arranged that the head is not allowed to fall forward upon the chest during sleep, a simple point first emphasised by Florence Nightingale. The weight of bedclothes should be taken by a cradle. Though the dying may want hot bottles or heaters, great care is necessary to avoid burns; usually as the skin temperature falls the internal temperature rises, and discomfort is not from a sensation of cold but from Libyan heat and thirst. The proper treatment then is fewer bed clothes and better ventilation, with warm sponging, frequent cool acid drinks and the use of simple sialogogues. This intense thirst and the dirty mouth that goes with it need constant attention. Cleansing should be done every hour or two if necessary, with swabs of cotton wool, soaked in glycerin with borax or hydrogen peroxide, twisted round orange sticks or held in forceps. Chewing pineapple is an excellent help to a dirty mouth, and acid drops, chewing gum or a simple mixture with a little ether increase salivation when the patient is still able to co-operate.

Bed sores are one of the banes of the dying, and their prevention turns upon scrupulous attention to pressure points. The cardinal needs are frequent changes of posture, washing, light massage, hardening the skin with surgical spirit and powdering afterwards, every few hours if necessary. In the treatment of bed sores there is no royal road to success, shown by the many methods that have been tried. Surrounds must be relieved of weight so far as possible, and dry heat and friction also help. Among newer methods for treating sores Streptocide powder and 
the application of a firm Elastoplast strip, or light packing with Io per cent Zinc Peroxide and 5 per cent Scarlet Red in soft paraffin are both successful.

Here we need to dismiss so-called "Stimulants," such as strychnine, adrenalin, camphor in oil or ether injected, which are variously regarded as improving the efficiency of the circulation or respiration. A former vogue has passed with the critical inquiry which their actions have received. For these are always brief, so often trivial, and rarely, if ever, affect the issue in a dying man.

This brings us to a debatable problem, acceleration of death in the dying. The legal and moral issues which focus on this matter are intricate and can barely be dealt with here; but a few points are outstanding. In the first place the law forbids in theory but ignores in practice, thus tacitly accepting the commonsense view that doctors here, as in other spheres, should be protected from the consequences of steps honestly taken in the interests of patients. It needs to be satisfied only as to the skill and judgment exercised. If there are occasions when hastening death seems the most sensible and humane procedure the proper course then becomes a matter for one's own conscience, and a guide to conduct is found by regarding the circumstances as affecting a close personal relative. The first essential on these occasions is to keep one's own counsel, Nothing should ever be done at the request of third parties. As for the means, morphine in quickly cumulative doses is one of the best. Insulin produces unconsciousness easily; as little as 40 units may be fatal to a cachectic patient, while others need much more. Venesection is unreliable. Relatives should be warned that the patient is worse, and is reaching unconsciousness rapidly. One other point about such treatment-the doctor should always give the drug himself, for he takes the direct responsibility in that way.

Family doctors may need to advise the dying in arranging financial affairs; in this connection testamentary capacity has to be considered. On rarer occasions a dying declaration must be taken for a criminal action at law.

I have dealt so far with what seem to me the leading topics in the care of the dying; but we have to think of others also in discharging our task. One important thing is that relatives should be assured that means of relief are effective; and at times persuaded also of the euthanasia which nature so often provides. Though so rarely need patients learn of impending death ${ }^{\circ}$ responsible relations have to know. There is a choice of time and persons for such tidings, especially with an emotional family. A colleague may give invaluable help, for the obligation upon a second opinion is also to temper truth with hope, a course from which no reputation ever suffers. You will find yourselves dealing with many unexpected situations among the dying. Sometimes death brings family discord, sometimes imposes obligations on one particular member of a family; or maybe the loss is of one who for years has kept that family together as individuals will. . Here I would remind you that we do not always give our drugs to the patient at a death bed scene, but rather to relations.

Much of what I have told you to-day is outside the scope of your curriculum, and little of it will help you to pass examinations. But I hope that it will make you think of the dying and their problems before you have to deal with them. For our profession spend a great part of their time among such problems, a part just as important as others. Oliver Wendell Holmes used to say that while one of the physician's functions is to assist at the coming-in, another is to assist at the going-out. Alfred Worcester has expressed it another way when he wrote, "Our duty to our patients ends only with their death, and in the preceding hours there is much that we can do for their comfort. At the very least we can stand by them." To do so creditably requires not only skill but inexhaustible patience.

\section{RFFRRENCES}

BURNEY YEO, I., A Manual of Medical Treatment or Clinical Therapeutics. London, Cassell, Ig08.

PARKES WEBER, F., Aspects of Death and Correlated Aspects of Life in Art, Epigram, and Poetry. 3rd Edition. Unwin \& Quaritch. London, I918.

RYLE, J. A. Lancet, 1940, 239, 401.

WORCESTER, A., The Care of the Aged, the Dying and the Dead. and Edition. Thomas, Springfield, r940.

We wish to thank the Editors of the King's College Hospital Gazette and the Brompton Hospital Reports for permission to reproduce this article. 